\title{
Investigating the Antibacterial Effect of Passive Ultrasonic Irrigation, Photodynamic Therapy and Their Combination on Root Canal Disinfection
}

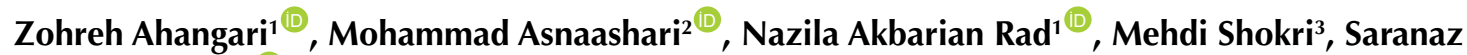 \\ Azari-Marhabi $^{*}{ }^{*}$, Negin Asnaashari ${ }^{2}$ \\ 'Department of Endodontics, School of Dentistry, Shahid Beheshti University of Medical Sciences, Tehran, Iran \\ ${ }^{2}$ Laser Application in Medical Sciences Research Center, Shahid Beheshti University of Medical Sciences, Tehran, Iran \\ ${ }^{3}$ Department of Dental Biomaterials, School of Dentistry, Shahid Beheshti University of Medical Sciences, Tehran, Iran
}

\section{*Correspondence to}

Saranaz Azari-Marhabi, Laser Application in Medical Sciences Research Center, Shahid Beheshti University of Medical Sciences, Tehran, Iran

Received: August 1, 2021 Accepted: October 6, 2021 Published online 25 December 2021

\begin{abstract}
Introduction: Enterococcus faecalis is a gram-positive, facultative anaerobic bacterium associated with persistent endodontic infections. Conventional disinfection methods may not completely eradicate the bacteria within the root canal system. Therefore, novel modalities have been suggested to optimize root canal disinfection. The aim of this study was to evaluate and compare the antibacterial effect of photodynamic therapy (PDT), passive ultrasonic irrigation (PUI) and their combination in addition to conventional endodontic irrigation against $E$. faecalis biofilms in root canals.

Methods: Root canals of 50 single-rooted extracted human teeth were prepared and incubated with $E$. faecalis for 21 days. They were then divided into 4 treatment groups and a control group as follows: (1) $\mathrm{NaOCl}$-Syringe irrigation with 2.5\% NaOCl, (2) PUI-Passive ultrasonic irrigation with $\mathrm{NaOCl}$, (3) $\mathrm{NaOCl}+\mathrm{PDT}$-Photodynamic therapy following syringe irrigation with $\mathrm{NaOCl}$ (4) PUI+PDT, (5) Control-Syringe irrigation with saline. Colony-forming units were counted and bacterial reduction was calculated for each treatment group.

Results: All treatments led to significant reductions in the bacterial load compared to the control group. PUI and PUI+PDT led to the complete elimination of the bacteria from the root canals. $\mathrm{NaOCl}$ and $\mathrm{NaOCl}+\mathrm{PDT}$ treatments reduced the bacteria by $99.9 \%$ and $99.5 \%$ respectively. $\mathrm{NaOCl}+\mathrm{PDT}$ was significantly less effective in reducing the bacteria compared to other treatment groups. There were no significant differences between the $\mathrm{NaOCI}$, PUI, and PUI+PDT groups.

Conclusion: Passive ultrasonic irrigation with or without the combination of Photodynamic therapy completely eradicated the bacteria. The use of PDT as an adjunction to $\mathrm{NaOCl}$ syringe irrigation and PUI did not enhance their antibacterial effect.

Keywords: Antimicrobial photodynamic therapy; Passive ultrasonic irrigation; Sodium hypochlorite; Enterococcus faecalis
\end{abstract}

\section{Introduction}

Persistent intraradicular infection is a major cause of endodontic treatment failure. ${ }^{1}$ Therefore, efficient disinfection of the root canal system is of great importance. ${ }^{2}$ Due to the complex anatomy of the root canals ${ }^{3,4}$ and resistance of bacterial biofilms to disinfectants, ${ }^{5}$ conventional methods of chemomechanical preparation are not able to completely eradicate the bacteria within the root canal system. ${ }^{4,6}$ Following instrumentation and $\mathrm{NaOCl}$ irrigation, approximately $40 \%-60 \%$ of the canals remain infected with cultivable bacteria. ${ }^{7}$ According to a research study, a negative culture before the root canal obturation resulted in a success rate of $94 \%$, while a positive culture reduced the success rate to $68 \%{ }^{8}$

Enterococcus faecalis is the most commonly detected species in the previously root canal-filled teeth with persistent periradicular lesions. ${ }^{1,9}$ Different factors including its ability to form biofilms, competition with other microorganisms, invading dentinal tubules, and survival in nutritional starvation contribute to its resistance and high prevalence. ${ }^{9}$

Novel modalities such as irrigant activation methods and photodynamic therapy (PDT) have been investigated to optimize root canal disinfection techniques. ${ }^{10-14}$

The effectiveness of intracanal irrigants relies on their direct contact with the root canal walls. The fluid exchange caused by conventional endodontic irrigation with a syringe and needle does not exceed $1 \mathrm{~mm}$ from the needle tip. ${ }^{14,15}$ Moreover, the apical vapor lock created during syringe irrigation hinders irrigant displacement at

Please cite this article as follows: Ahangari Z, Asnaashari M, Akbarian Rad N, Shokri M, Azari-Marhabi S, Asnaashari N. Investigating the antibacterial effect of passive ultrasonic irrigation, photodynamic therapy and their combination on root canal disinfection. J Lasers Med Sci. 2021;12:e81. doi:10.34172/jlms.2021.81. 
the apical third of the root canal system. ${ }^{15,16}$ To overcome these limitations, the activation/agitation of the irrigants using different techniques including manual dynamic activation, passive ultrasonic irrigation, sonic irrigation and laser-activated irrigation has been proposed. ${ }^{14,17}$

Passive ultrasonic irrigation (PUI) is one of the most widely used irrigant activation systems ${ }^{16}$ in which the acoustic energy is transmitted from an oscillating noncutting file or smooth wire to the irrigating solution in the prepared root canal through ultrasonic waves, leading to acoustic streaming and cavitation of the irrigant. ${ }^{13}$ This procedure may enhance the penetration of the disinfecting irrigants, increasing their antimicrobial efficacy. ${ }^{18}$

PDT is a treatment characterized by the inactivation of cells, microorganisms, or molecules by means of a light of a specific wavelength. ${ }^{19}$ The exposure of a non-toxic dye (photosensitizer) to light in the presence of oxygen leads to the generation of highly reactive chemical species, such as singlet oxygen and free radicals which induce cell death. $^{20}$

Several studies have been carried out to evaluate the antimicrobial efficacy of PDT (or PAD: photo-activated disinfection) in root canal treatment. ${ }^{621-24}$ Although conflicting results exist regarding its superiority over other decontamination strategies, preclinical data recommend PDT as a promising adjunctive method to the conventional chemomechanical preparation for further bacterial reduction. ${ }^{11,12}$

PDT can be performed by lasers, LED and halogen lamps. ${ }^{25}$ The use of LED as a safer light source for PDT leads to less heat generation ${ }^{26}$ and consequently less tissue injury.

The present study aimed to evaluate and compare the efficacy of PUI, LED-mediated PDT in adjunction with the routine $\mathrm{NaOCl}$ irrigation, and their combination in root canal disinfection.

\section{Materials and Methods Specimen Preparation}

Fifty-five single-rooted extracted human teeth (incisors and single-rooted premolars) with intact, fully developed roots were collected. The presence of a single canal was radiographically confirmed. The teeth were stored and disinfected in $5.25 \%$ sodium hypochlorite $(\mathrm{NaOCl})$ solution for 24 hours. They were then stored in sterile $0.9 \%$ saline solution at room temperature before the experiment.

The teeth were decoronated and the roots were shortened to a length of approximately $12 \mathrm{~mm}$ using a water-cooled diamond disk. The root canals were prepared using ProTaper Gold rotary files (Dentsply Maillefer, Tulsa, OK, USA) to a master apical file size F3. During all preparation steps, irrigation was performed with $10 \mathrm{~mL}$ of sterile saline solution.

After mechanical instrumentation, root canals were irrigated with $17 \%$ Ethylenediaminetetraacetic acid
(EDTA) solution for 2 minutes followed by irrigation with $5.25 \% \mathrm{NaOCl}$ for 2 minutes to remove the smear layer. They were finally rinsed with sterile saline solution to eliminate the remaining irrigants. The apical ends of the roots were sealed with composite resin.

The roots were individually immersed in test tubes containing $1 \mu \mathrm{L}$ of Brain heart infusion (BHI) broth (Merck, Darmstadt, Germany), and they were then sterilized in an autoclave at a temperature of $121^{\circ} \mathrm{C}$ and a pressure of 15 Psi for 15 minutes. To verify the absence of bacterial contamination, 5 specimens were randomly selected. Samples were taken from the root canals and cultured on agar plates. No bacterial growth was detected after 24 hours.

\section{Root Canal Contamination and Biofilm Formation}

Root canals were contaminated with Enterococcus faecalis (ATCC9854) taken from a frozen stock as follows: $0.5 \mathrm{~mL}$ of a suspension containing E. faecalis bacteria equivalent to $0.5 \mathrm{McF}$ arland was inoculated to the tubes containing $0.5 \mathrm{ml}$ of BHI broth medium (Merck, Darmstadt, Germany) and sterile dental specimens. After the vortex, for bacterial biofilm formation and further penetration of the bacteria into the dentinal tubules, all the tubes were incubated at $37^{\circ} \mathrm{C}$ for 21 days. During this period the BHI media were refreshed on alternate days, and each time the tubes were swirled individually using a vortex mixer so that the medium and the bacteria could completely penetrate into the dentinal tubules.

\section{Treatment Groups}

The roots were placed in a 96-well plate and randomly assigned into 4 treatment groups $(\mathrm{n}=10)$ and a control group $(\mathrm{n}=10)$ using a random number table.

Group 1 ( $\mathrm{NaOCl})$ : Root canal irrigation with $\mathrm{NaOCl}$ using a syringe and a 30 -gauge needle placed $1 \mathrm{~mm}$ short of the apices

Group 2 (PUI): Passive ultrasonic irrigation

Group 3 ( $\mathrm{NaOCl}+\mathrm{PDT})$ : Photodynamic therapy following $\mathrm{NaOCl}$ irrigation

Group 4 (PUI+PDT): Passive ultrasonic irrigation followed by photodynamic therapy

Control group: Root canal irrigation with $10 \mathrm{ml}$ of normal saline using a syringe and a 30-gauge needle placed $1 \mathrm{~mm}$ short of the apices

In all treatment groups following $\mathrm{NaOCl}$ irrigation, the solution was rinsed off the root canals using $10 \mathrm{ml}$ of normal saline. In groups 1 and 3, the root canals were irrigated with $10 \mathrm{ml}$ of $2.5 \% \mathrm{NaOCl}$ for 2 minutes without activation.

\section{Passive Ultrasonic Irrigation}

Following 90 -second syringe irrigation with $10 \mathrm{ml}$ of $2.5 \%$ $\mathrm{NaOCl}$, the solution was activated by a \#25 Ufile (NSK Dental, Japan) driven by an NSK ultrasonic device (Varios 970 lux, NSK Dental, Japan) for 30 seconds. 


\section{Photodynamic Therapy}

The root canals were dried using sterile paper points and were then filled with toluidine blue solution $(0.1 \mathrm{mg} / \mathrm{mL})$. The solution remained in the canals for 1 minute. PDT was performed using an ENDO tip of $0.5 \mathrm{~mm}$ diameter and a light-emitting diode (LED) (FotoSan ${ }^{\circledR} 630$, CMS dental, Denmark) with a power peak at $630 \mathrm{~nm}$ and output intensity of $2000-4000 \mathrm{mw} / \mathrm{cm}^{2}$ for 60 seconds (Energy density $=120-240 \mathrm{~J}$ ).

\section{Root Canal Sampling}

After the treatments, F4 ProTaper Gold rotary files (Dentsply Maillefer, Tulsa, OK, USA) driven by an NSK rotary motor (Endo-Mate DT, NSK Dental, Japan) were used in the root canals for 30 seconds at a speed of $250 \mathrm{rpm}$ and a torque of $1.5 \mathrm{~N} . \mathrm{cm}$. The files were then detached from the device and transferred into microtubes containing a liquid BHI medium using a sterile plier in order to culture the attached dentinal debris. During all sampling steps rotary files were not in contact with hands.

\section{Colony Counting}

The microtubes were vortexed and bacterial suspensions of each sample were diluted using 10 ten-fold serial dilutions. $100 \mu \mathrm{L}$ of the dilute solutions was plated on $8 \times 8 \mathrm{~cm}^{2} \mathrm{BHI}$ agar plates using the spread plate technique. The plates were incubated at $37^{\circ} \mathrm{C}$ for 24 hours. E. faecalis $\mathrm{CFU} / \mathrm{mL}$ was calculated using a colony counter (Teif Azma Teb, Iran).

\section{Sample Preparation for SEM Imaging}

In order to confirm the biofilm formation in the canals, one specimen was prepared for scanning electron microscopy imaging. For this reason, after preparation of the root canal 2 grooves were made on buccal and lingual surfaces of the root by a fissure diamond bur. The specimen was inoculated with $E$. faecalis and incubated at $37^{\circ} \mathrm{C}$ for 21 days. Then it was split into halves using a sterile chisel. The tooth sections were fixed in $2.5 \%$ glutaraldehyde solution at $4^{\circ} \mathrm{C}$ for 24 hours (Figure 1).

\section{Statistical Analysis}

The Kruskal-Wallis test was applied to compare the final
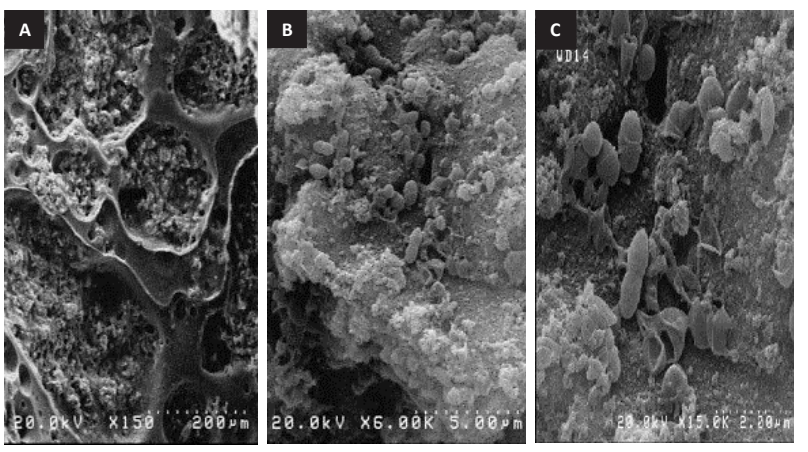

Figure 1. SEM Images of the Root Canal Wall After 3-Week Incubation With Enterococcus faecalis: A (150x), B (6000x), C (15000x).
CFU counts among the 5 treatment groups, and pairwise comparisons of the groups were performed using the Mann-Whitney $\mathrm{U}$ test. $P$ value $<0.05$ was considered to be statistically significant. The data were analyzed using the GraphPad Prism 7 software (Figure 2).

\section{Results}

The mean colony counts $(\mathrm{CFU} / \mathrm{mL})$ of $E$. faecalis bacteria remaining in the root canals after treatments are presented in Table 1. The mean CFU in the control group served as the baseline for comparison. In all treatment groups, CFUs of E. faecalis significantly decreased compared to the control group, with the [PUI] and [PUI+PDT] treatments achieving a $100 \%$ reduction (Table 1). Bacterial reduction in groups [PUI], [PUI+PDT], and $[\mathrm{NaOCl}]$ was significantly higher than that of the $[\mathrm{NaOCl}+\mathrm{PDT}]$ group. There were no significant differences between the [NaOCl], [PUI], and [PUI+PDT] groups (Table 2).

\section{Discussion}

The present study evaluated the antibacterial effect of PDT, PUI and their combination in adjunction to the routine application of $\mathrm{NaOCl}$ on root canals infected with E. faecalis biofilms.

Enterococcus faecalis was selected considering its ability to colonize root canals in biofilms and its resistance to antimicrobial agents. ${ }^{2}$ In order to simulate

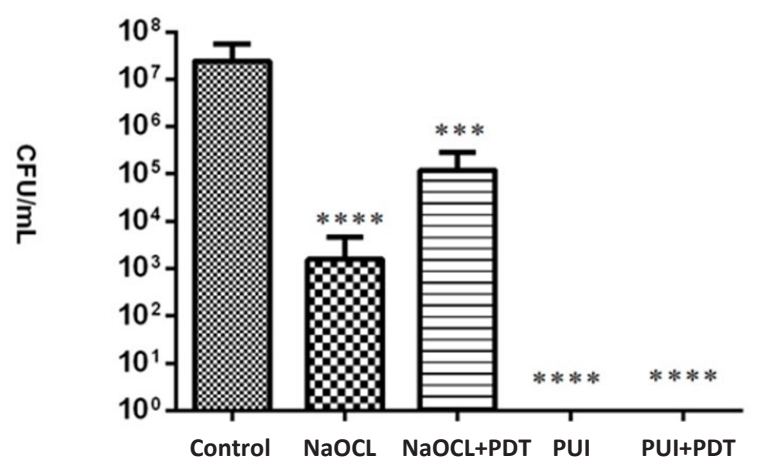

Figure 2. Enterococcus faecalis CFU/mL After Disinfection Protocols. The error bars indicate the mean $\mathrm{CFU} \pm \mathrm{SD}$. The asterisks represent statistically significant reductions relative to the control group $\left({ }^{*} P<0.05\right.$, $* * P<0.01$, $* * * P<0.001, * * * * P<0.0001)$.

Table 1. CFU/mL Counts of Enterococcus faecalis and Percentage of Bacterial Reduction After Antibacterial Treatments

\begin{tabular}{lccc}
\hline Group & $\begin{array}{c}\text { Bacterial Reduction } \\
\text { Relative to the } \\
\text { Control Group (\%) }\end{array}$ & $\begin{array}{c}\text { Mean CFU/mL } \\
\text { After Treatment }\end{array}$ & $\boldsymbol{P}$ Value \\
\hline Control & - & $2.4 \times 10^{7}$ & - \\
$\mathrm{NaOCl}$ & 99.93 & $1.5 \times 10^{4}$ & $<0.0001$ \\
$\mathrm{NaOCl}+\mathrm{PDT}$ & 99.5 & $1.21 \times 10^{5}$ & 0.0002 \\
$\mathrm{PDT}+\mathrm{PUI}$ & 100 & 0.0 & $<0.0001$ \\
$\mathrm{PUI}$ & 100 & 0.0 & $<0.0001$ \\
\hline CFUs, colony-forming & units; PDT, photodynamic therapy; PUI, passive \\
ultrasonic irrigation. & & &
\end{tabular}


Table 2. The Results of Pairwise Comparison of the Groups Using MannWhitney Test

\begin{tabular}{lcccc}
\hline & NaOCL & NaOCl+PDT & PUI & PUI+PDT \\
\hline NaOCL & - & $P=0.00028$ & $P=0.08$ & $P=0.08$ \\
NaOCl+PDT & $P=0.00028$ & - & $P<0.0001$ & $P<0.0001$ \\
PUI & $P=0.08$ & $P<0.0001$ & - & $P>0.9999$ \\
PUI+PDT & $P=0.08$ & $P<0.0001$ & $P>0.9999$ & - \\
\hline
\end{tabular}

PDT, photodynamic therapy; PUI, passive ultrasonic irrigation.

the in vivo situation, a biofilm model was used in this research. Bacteria within a biofilm are less susceptible to antimicrobials compared to their planktonic counterparts. This may be due to the biofilm-specific protection against oxidative stress, biofilm-specific expression of efflux pumps, and decreased penetration of antimicrobial agents through the biofilm matrix. ${ }^{27,28}$ Shen et al reported that the bacteria in mature (3-week old) biofilms were more resistant to antimicrobial treatments than those in young biofilms. ${ }^{29}$ Therefore, in the present study, the root canals were incubated with $E$. faecalis for 3 weeks.

Given that $\mathrm{NaOCl}$ is the "gold standard" irrigant for root canal disinfection, ${ }^{30}$ in this study, irrigation with $\mathrm{NaOCl}$ was carried out in the samples of all treatment groups (PDT, PUI, and PUI+PDT) to evaluate the combination effect.

The results showed that all treatments caused a significant reduction in the CFUs of E. faecalis within the root canals. This reduction was significantly higher in the PUI, PUI+PDT, and 2.5\% NaOCl treatments compared to $\mathrm{NaOCl}+\mathrm{PDT}$. PUI with or without PDT eradicated the bacteria within the root canal system.

PDT acts through the activation of a photosensitizer by exposure to a light at a compatible wavelength. ${ }^{4,12}$ In this study, toluidine blue was employed in PDT, which is a common type of photosensitizer used in numerous studies. , $3,36,31-34^{2}$ FotoSan 630 was used as the light source, emitting light in the red spectrum with peak power at $630 \mathrm{~nm}$.

Rios et $\mathrm{al}^{34}$ evaluated the antimicrobial effect of PDT using an LED and toluidine blue. The Results demonstrated that PDT in adjunction to $6 \% \mathrm{NaOCl}$ irrigation led to a greater reduction of the bacteria compared to the sole use of PDT or $\mathrm{NaOCl}$ irrigation. Likewise, de Oliveira et $\mathrm{al}^{35}$ reported that the association of $5.25 \% \mathrm{NaOCl}$ irrigation with PDT using a diode laser and methylene blue resulted in significant additional antimicrobial effect against $E$. faecalis compared to the $\mathrm{NaOCl}$ irrigation alone, whereas in the present study CFU reduction caused by $2.5 \%$ $\mathrm{NaOCl}$ irrigation was greater than that of adjunctive PDT. This difference may be attributed to the use of sodium thiosulfate for $\mathrm{NaOCl}$ inactivation in the aforementioned study. In the current study, the remaining $\mathrm{NaOCl}$ in the dentinal tubules may have restricted the penetration of the photosensitizer or negated its effect, and thus interfered with the function of PDT. Furthermore, the use of a different PDT protocol and a more mature biofilm model in the present study may have led to the reduced effect of PDT. It should be noted that in clinical practice, sodium thiosulfate is not commonly used after root canal irrigation with $\mathrm{NaOCl}$.

In the present study, PUI yielded the best bactericidal effects (100\% bacterial reduction) which were significantly greater than those of syringe irrigation and adjunctive PDT. Similarly, studies conducted by Mohammed et al. and Eneide et al demonstrated superior antibiofilm efficacy of PUI over syringe irrigation. ${ }^{36,37}$ The acoustic microstreaming and cavitation created by PUI produce shear stress, disrupting the bacterial biofilm on the root canal walls. ${ }^{16}$

Xhevdet et $\mathrm{al}^{38}$ compared the disinfection efficacy of PDT, $\mathrm{NaOCl}$ irrigation and PUI. The results showed that while PDT caused a significant decrease in microorganisms, ultrasonic irrigation was more effective in reducing the bacterial load, which is in accordance with the findings of the present study.

Wang et $\mathrm{al}^{39}$ investigated the synergistic antibacterial effect of MB-mediated PDT and ultrasonic irrigation with $\mathrm{NaOCl}$ on E. faecalis bacteria within the root canals of bovine incisors. They found the combination treatment to be significantly more effective than standalone treatments. In the present study, although the combination treatment led to the complete elimination of the bacteria, no synergistic effect was found between PDT and PUI.

\section{Conclusion}

Within the limitations of this study ultrasonic activation of $2.5 \% \mathrm{NaOCl}$ solution resulted in the complete elimination of the bacteria within the root canals. The adjunction of PDT to $\mathrm{NaOCl}$ irrigation did not enhance the antibacterial effect.

\section{References}

1. Siqueira JF, Rôças IN. Present status and future directions in endodontic microbiology. Endod Topics. 2014;30(1):322. doi:10.1111/ETP.12060

2. Bago I, Plečko V, Gabrić Pandurić D, Schauperl Z, Baraba A, Anić I. Antimicrobial efficacy of a high-power diode laser, photo-activated disinfection, conventional and sonic activated irrigation during root canal treatment. Int Endod J. 2013;46(4):339-47. doi: 10.1111/j.13652591.2012.02120.x..

3. Moradi Eslami L, Vatanpour M, Aminzadeh N, Mehrvarzfar P, Taheri S. The comparison of intracanal medicaments, diode laser and photodynamic therapy on removing the biofilm of Enterococcus faecalis and Candida albicans in the root canal system (ex-vivo study). Photodiagnosis Photodyn Ther. 2019;26:157-161. doi: 10.1016/j.pdpdt.2019.01.033.

4. Lane J, Bonsor S. Survival rates of teeth treated with bacterial photo-dynamic therapy during disinfection of the root canal system. Br Dent J. 2019;226(5):333-339. doi: 10.1038/s41415-019-0026-z.

5. Neelakantan P, Romero M, Vera J, Daood U, Khan AU, Yan 
A, et al. Biofilms in Endodontics-Current Status and Future Directions. Int J Mol Sci. 2017;18(8):1748. doi: 10.3390/ ijms18081748.

6. De Meyer S, Meire MA, Coenye T, De Moor RJ. Effect of laser-activated irrigation on biofilms in artificial root canals. Int Endod J. 2017;50(5):472-479. doi: 10.1111/ iej.12643.

7. Tennert C, Drews AM, Walther V, Altenburger MJ, Karygianni L, Wrbas KT, et al. Ultrasonic activation and chemical modification of photosensitizers enhances the effects of photodynamic therapy against Enterococcus faecalis root-canal isolates. Photodiagnosis Photodyn Ther. 2015;12(2):244-51. doi: 10.1016/j.pdpdt.2015.02.002.

8. Sjögren U, Figdor D, Persson S, Sundqvist G. Influence of infection at the time of root filling on the outcome of endodontic treatment of teeth with apical periodontitis. Int Endod J. 1997;30(5):297-306. doi: 10.1046/j.13652591.1997.00092.x.

9. Stuart $\mathrm{CH}$, Schwartz SA, Beeson TJ, Owatz CB. Enterococcus faecalis: Its role in root canal treatment failure and current concepts in retreatment. J Endod. 2006;32(2):93-8. doi: 10.1016/j.joen.2005.10.049.

10. Căpută PE, Retsas A, Kuijk L, Chávez de Paz LE, Boutsioukis C. Ultrasonic Irrigant Activation during Root Canal Treatment: A Systematic Review. J Endod. 2019;45(1):3144.e13. doi: 10.1016/j.joen.2018.09.010.

11. Pourhajibagher M, Bahador A. Adjunctive antimicrobial photodynamic therapy to conventional chemo-mechanical debridement of infected root canal systems: A systematic review and meta-analysis. Photodiagnosis Photodyn Ther. 2019;26:19-26. doi: 10.1016/j.pdpdt.2019.02.009.

12. Plotino G, Grande NM, Mercade M. Photodynamic therapy in endodontics. Int Endod J. 2019; 52(6):760-774. doi: 10.1111/iej.13057.

13. Silva EJNL, Rover G, Belladonna FG, Herrera DR, De-Deus G, da Silva Fidalgo TK. Effectiveness of passive ultrasonic irrigation on periapical healing and root canal disinfection: a systematic review. Br Dent J. 2019; 227(3):228-234. doi: 10.1038/s41415-019-0532-z.

14. Walsh LJ, George R. Activation of alkaline irrigation fluids in endodontics. Materials (Basel). 2017;10(10):1214. doi: 10.3390/ma10101214.

15. Saber Sel-D, Hashem AA. Efficacy of different final irrigation activation techniques on smear layer removal. $J$ Endod. 2011;37(9):1272-5. doi: 10.1016/j.joen.2011.06.007.

16. Nagendrababu V, Jayaraman J, Suresh A, Kalyanasundaram S, Neelakantan P. Effectiveness of ultrasonically activated irrigation on root canal disinfection: a systematic review of in vitro studies. Clin Oral Investig. 2018;22(2):655-670. doi: 10.1007/s00784-018-2345-x.

17. Virdee SS, Seymour DW, Farnell D, Bhamra G, Bhakta S. Efficacy of irrigant activation techniques in removing intracanal smear layer and debris from mature permanent teeth: a systematic review and meta-analysis. Int Endod J. 2018; 51(6):605-621. doi: 10.1111/iej.12877.

18. Niavarzi S, Pourhajibagher M, Khedmat S, Ghabraei S, Chiniforush N, Bahador A. Effect of ultrasonic activation on the efficacy of antimicrobial photodynamic therapy: Evaluation of penetration depth of photosensitizer and elimination of Enterococcus faecalis biofilms.
Photodiagnosis Photodyn Ther. 2019;27:362-366. doi: 10.1016/j.pdpdt.2019.06.001.

19. Rosa RAD, Santini MF, Figueiredo JAP, Visioli F, Pereira JR, Vivan RR, et al. Effectiveness of photodynamic therapy associated with irrigants over two biofilm models. Photodiagnosis Photodyn Ther. 2017; 20:169-174. doi: 10.1016/j.pdpdt.2017.10.003.

20. Konopka K, Goslinski T. Photodynamic therapy in dentistry. J Dent Res. 2007;86(8):694-707. doi: $10.1177 / 154405910708600803$.

21. Hoedke D, Enseleit C, Gruner D, Dommisch H, Schlafer S, Dige I, et al. Effect of photodynamic therapy in combination with various irrigation protocols on an endodontic multispecies biofilm ex vivo. Int Endod J. 2018;51 (Suppl 1):e23-e34. doi: 10.1111/iej.12763.

22. Bonsor SJ, Nichol R, Reid TM, Pearson GJ. Microbiological evaluation of photo-activated disinfection in endodontics (an in vivo study). Br Dent J. 2006;200(6):337-329. doi:10.1038/sj.bdj.4813371

23. Garcez AS, Nuñez SC, Hamblim MR, Suzuki H, Ribeiro MS. Photodynamic therapy associated with conventional endodontic treatment in patients with antibiotic-resistant microflora: a preliminary report. J Endod. 2010 ;36(9):14636. doi: 10.1016/j.joen.2010.06.001.

24. Chiniforush N, Pourhajibagher M, Shahabi S, Kosarieh E, Bahador A. Can Antimicrobial Photodynamic Therapy (aPDT) enhance the Endodontic Treatment? J Lasers Med Sci. 2016;7(2):76-85. doi: 10.15171/jlms.2016.14.

25. Nagata JY, Hioka N, Kimura E, Batistela VR, Terada RS, Graciano AX, et al. Antibacterial photodynamic therapy for dental caries: evaluation of the photosensitizers used and light source properties. Photodiagnosis Photodyn Ther. 2012 ;9(2):122-31. doi: 10.1016/j.pdpdt.2011.11.006.

26. Schlafer S, Vaeth M, Hørsted-Bindslev P, Frandsen EV. Endodontic photoactivated disinfection using a conventional light source: an in vitro and ex vivo study. Oral Surg Oral Med Oral Pathol Oral Radiol Endod. 2010;109(4):634-41. doi: 10.1016/j.tripleo.2009.12.027.

27. wimberghe RCD, Coenye T, De Moor RJG, Meire MA. Biofilm model systems for root canal disinfection: a literature review. Int Endod J. 2019;52(5):604-628. doi: 10.1111/iej.13050.

28. Van Acker H, Van Dijck P, Coenye T. Molecular mechanisms of antimicrobial tolerance and resistance in bacterial and fungal biofilms. Trends Microbiol. 2014; 22(6):326-33. doi: 10.1016/j.tim.2014.02.001.

29. Shen Y, Stojicic S, Haapasalo M. Antimicrobial efficacy of chlorhexidine against bacteria in biofilms at different stages of development. J Endod. 2011;37(5):657-61. doi: 10.1016/j.joen.2011.02.007.

30. Prada I, Micó-Muñoz P, Giner-Lluesma T, Micó-Martínez P, Muwaquet-Rodríguez S, Albero-Monteagudo A. Update of the therapeutic planning of irrigation and intracanal medication in root canal treatment. A literature review. J Clin Exp Dent. 2019 ;11(2):e185-e193. doi: 10.4317/ jced.55560.

31. Asnaashari M, Mojahedi SM, Asadi Z, Azari-Marhabi S, Maleki A. A comparison of the antibacterial activity of the two methods of photodynamic therapy (using diode laser $810 \mathrm{~nm}$ and LED lamp $630 \mathrm{~nm}$ ) against Enterococcus 
faecalis in extracted human anterior teeth. Photodiagnosis Photodyn Ther. 2016; 13:233-237. doi: 10.1016/j. pdpdt.2015.07.171.

32. Muhammad OH, Chevalier M, Rocca JP, Brulat-Bouchard $\mathrm{N}$, Medioni E. Photodynamic therapy versus ultrasonic irrigation: Interaction with endodontic microbial biofilm, an ex vivo study. Photodiagnosis Photodyn Ther. 2014; 11(2):171-81. doi: 10.1016/j.pdpdt.2014.02.005

33. Samiei M, Shahi S, Abdollahi AA, Eskandarinezhad M, Negahdari R, Pakseresht Z. The Antibacterial Efficacy of Photo-Activated Disinfection, Chlorhexidine and Sodium Hypochlorite in Infected Root Canals: An in Vitro Study. Iran Endod J. 2016; 11(3):179-183. doi:10.7508/ iej.2016.03.006.

34. Rios A, He J, Glickman GN, Spears R, Schneiderman ED, Honeyman AL. Evaluation of photodynamic therapy using a light-emitting diode lamp against Enterococcus faecalis in extracted human teeth. J Endod. 2011; 37(6):856-9. doi: 10.1016/j.joen.2011.03.014.

35. de Oliveira BP, Aguiar CM, Câmara AC, de Albuquerque MM, Correia AC, Soares MF. The efficacy of photodynamic therapy and sodium hypochlorite in root canal disinfection by a single-file instrumentation technique. Photodiagnosis Photodyn Ther. 2015; 12(3):436-43. doi: 10.1016/j. pdpdt.2015.05.004.

36. Mohmmed SA, Vianna ME, Penny MR, Hilton ST, Mordan NJ, Knowles JC. Investigations into in situ Enterococcus faecalis biofilm removal by passive and active sodium hypochlorite irrigation delivered into the lateral canal of a simulated root canal model. Int Endod J. 2018; 51(6):649662. doi: 10.1111/iej.12880.

37. Eneide C, Castagnola R, Martini C, Grande NM, Bugli F, Patini R, et al. Antibiofilm activity of three different irrigation techniques: an in vitro study. Antibiotics (Basel). 2019;8(3):112. doi: 10.3390/antibiotics8030112.

38. Xhevdet A, Stubljar D, Kriznar I, Jukic T, Skvarc M, Veranic $\mathrm{P}$, et al. The disinfecting efficacy of root canals with laser photodynamic therapy. J lasers Med Sci. 2014;5(1):19-26.

39. Wang Y, Huang X. Comparative antibacterial efficacy of photodynamic therapy and ultrasonic irrigation against Enterococcus faecalis in vitro. Photochem Photobiol. 2014; 90(5):1084-8. doi: 10.1111/php.12293. 